\title{
Effects of early psychosocial deprivation on the development of memory and executive function
}

\author{
Karen J. Bos ${ }^{1}$, Nathan Fox ${ }^{2}$, Charles H. Zeanah ${ }^{3}$ and Charles A. Nelson III ${ }^{1,4}$ * \\ Harvard Medical School and Harvard School of Public Health, Boston, MA, USA \\ 2 University of Maryland, College Park, MD, USA \\ 3 Tulane University School of Medicine, New Orleans, LA, USA \\ ${ }^{4}$ Children's Hospital Boston, Boston, MA, USA
}

\section{Edited by:}

Larry J. Young, Emory University School of Medicine, USA; Yerkes National Primate Research Center, USA

Reviewed by:

Megan Gunnar, University of Minnesota, USA

Michael Rutter, Kings College

London, UK

\section{*Correspondence:}

Charles A. Nelson III, Laboratories of Cognitive Neuroscience, Children's Hospital Boston, 1 Autumn Street, Office AU621, Mailbox \#713, Boston, MA 02115-5365, USA.

e-mail:charles.nelson@childrens. harvard.edu

\begin{abstract}
This study investigated the effects of early institutional care on memory and executive functioning. Subjects were participants in the Bucharest Early Intervention Project (BEIP) and included institutionalized children, children with a history of institutionalization who were assigned to a foster care intervention, and community children in Bucharest, Romania. Memory and executive functioning were assessed at the age of 8 years using the Cambridge NeuropsychologicalTest and Automated Battery (CANTAB). As expected, children with a history of early institutional care performed worse on measures of both visual memory and executive functioning compared to their peers without a history of institutional care. In comparing children randomly assigned to the foster care intervention with their peers who had continued care in the institution, initial comparisons did not show significant differences on any of the memory or executive functioning outcomes. However, for one of the measures of executive functioning, after controlling for birth weight, head circumference, and duration of time spent in early institutional care, the foster care intervention was a significant predictor of scores. These results support and extend previous findings of deficits in memory and executive functioning among school-age children with a history of early deprivation due to institutional care. This study has implications for the millions of children who continue to experience the psychosocial deprivation associated with early institutional care.
\end{abstract}

Keywords: institutional care, memory, executive functioning

\section{INTRODUCTION}

Early psychosocial deprivation can lead to problems in social functioning, including indiscriminate behaviors, inattention/overactivity, and problems in forming adaptive social relationships with peers and adults (Chisholm, 1998; Kreppner et al., 2001; Zeanah et al., 2005). These effects appear to persist long after a child is placed in a family with stable and supportive caregiving. It is increasingly clear that the deficits and developmental delays that result from such deprivation have their origins in compromised brain development. In the sections below, we attempt to provide a conceptual framework for this observation.

Greenough et al. (1987) have argued that brain development is influenced by a combination of experience-expectant and experience-dependent mechanisms. The former refers to features of the environment that are theoretically common to all members of the species, whereas the latter refers to features of the environment that are unique to the individual. A short list of experience-expectant features of the environment might include access to a caregiver, adequate nutrition, sensory and cognitive stimulation, and linguistic input. While this list of environmental features may seem obvious, children reared in settings of profound deprivation — such as in institutions-lack most elements of what should be an "expectable" environment. This deprivation from environmental input during sensitive periods of development may lead to underspecification and miswiring of circuits in the immature nervous system.
Children reared under conditions of profound deprivation are not rare. By one estimate, there may be as many as $8,000,000$ children around the world living in institutions. Because of the prevalence of international adoption (in 2008, there were more than 17,000 children adopted from other countries by families in the U.S., see United States Department of State, 2009), a number of projects have been launched examining the long-term developmental consequences of institutionalization. In this paper we focus exclusively on cognitive outcomes. Previous research has identified a pattern of general intellectual impairment among children exposed to early institutional deprivation (Nelson et al., 2007; Smyke et al., 2007). Follow-up studies suggest that there are persistent effects of this deprivation on cognitive development into at least early adolescence (Beckett et al., 2006). However, our understanding of many fundamental questions about the developmental deficits and trajectories of these children remains limited. The contributions of specific underlying processes (such as memory, attention, perception, and problem solving) that may influence cognitive performance in this group are not clearly understood and warrant further investigation.

In one recent study, Colvert et al. (2008) of the English and Romanian Adoptees Study (ERAS) investigated possible deficits in two neuropsychological processes, theory of mind and executive functioning, among 11-year-old children adopted from Romanian institutions into the UK. To evaluate executive functioning, this 
study used the Stroop task to assess children's inhibitory control, as well as elements of cognitive flexibility, mental set shifting, and sustained attention. The authors found that children who had experienced early institutional deprivation showed significant deficits in executive function compared to either Romanian or UK children adopted at 6 months or younger (Colvert et al., 2008).

Pollak et al. (in press) also assessed neuropsychological functioning in $8-10$ year old adopted children with a history of institutional care, using the Cambridge Neuropsychological Test and Automated Battery (CANTAB) and the NEPSY Developmental Neuropsychological Assessment. Tasks were chosen to evaluate memory, learning, attention, and executive function. Three groups of children were studied: post-institutionalized internationally adopted children (defined as children adopted over age 12 months and having spent at least $75 \%$ of their lives prior to adoption in institutional care), early adopted children (defined as children adopted prior to 8 months of age, having spent 2 months or less in institutional care) and a group of control children raised by their birth families in the U.S. Post-institutionalized children differed from the other two groups on tests of visual memory, attention, and learning, as well as spatial working memory, a test of executive function.

In the current study, we further investigate memory and executive function in children with a history of early institutional care. We hope to clarify the possible contribution of these two domains to the general cognitive profile associated with such children. Doing so may help us identify the specific cognitive processes that may be particularly vulnerable to early psychosocial deprivation. This study, part of the Bucharest Early Intervention Project (BEIP), is unique in its ability to evaluate directly the effects of early family placement rather than institutional care for young children because the participants were institutionalized children randomly assigned either to continued care as usual in the institution or to a foster care intervention. The BEIP is the first such randomized clinical trial to evaluate foster care as an alternative to institutional care for abandoned children (see Zeanah et al., 2003, for details). Because the children enrolled in this study were closely followed longitudinally, this study also provides the unusual opportunity to investigate the effects of timing and duration of early institutional care on memory and executive function outcomes.

\section{RATIONALE FOR THE CURRENT PROJECT}

There is a strong scientific basis for the impact of early life stress on memory function. The hippocampus is known to be associated with normal memory function and is thought to develop early in life (see Richmond and Nelson, 2007 for recent reviews). Early adversity or stress can affect glucocorticoid receptors in regions of the hippocampus, resulting in chronically elevated levels of circulating glucocorticoids (McEwen, 2007). This damage to the hippocampus has been associated with memory impairments in animal and human studies, and neuroimaging studies have generally supported an association between hippocampal activity and the development of memory functioning (e.g., Curtis et al., 2002).

Though the current level of understanding of the biological basis for the impact of early deprivation on executive functioning is less well established, there is evidence that suggests that we would expect to see deficits in this area as well. The development of executive functioning is thought to coincide with growth spurts in the maturation of the prefrontal cortex, with these growth periods identified as between birth and 2 years of age, from 7 to 9 years, and during adolescence (Jurado and Rosselli, 2007). The circuits in the prefrontal cortex that support executive functioning have a long developmental trajectory and thus are thought to be particularly affected by experience, though the exact elements of that experience that matter are not yet known.

In this study we address the following questions: (1) Do children who have been exposed to early deprivation associated with institutional care perform differently on tests of visual memory and executive function than their peers without a history of early institutional care? (2) Among children who have a history of early institutional care, do children assigned to a foster care intervention perform differently than their peers who have continued care in the institution, and if so, is there an effect of age of placement into foster care or duration of institutional care? (3) Are there other likely variables that we can identify that may contribute to the findings in these domains among this group of children, such as birth weight or head circumference?

\section{MATERIALS AND METHODS PARTICIPANTS}

Participants for this study were children enrolled in the Bucharest Early Intervention Project (BEIP). The study includes children with a history of early institutional care (the ever-institutionalized group, or EIG) as well as a community comparison group of never-institutionalized children (NIG). Children in the everinstitutionalized group were placed in an institution on average at the age of 3.03 months ( $\mathrm{SD}=4.14$ months, range $0-17.49$ months), however, this age does not reflect that many abandoned children in Romania are temporarily cared for in a maternity hospital or other group setting prior to transfer to a formal institution, and thus the true mean age of entry into institutional care if these settings were included would be even lower. Prior to participation in the study, all children were screened with a pediatric and neurological assessment. Exclusion criteria included known genetic syndromes and frank signs of fetal alcohol syndrome.

Within the group of institutionalized children, each child was randomly assigned to one of two groups: foster care placement or continued care as usual in the institution. The average age at foster care placement was 23.6 months with a range of 9-33 months.

Demographics for the EIG and the NIG are presented in Table 1. At the time that testing was performed, the average age for children in the ever-institutionalized group was about 1 month older than children in the never-institutionalized group. The ever-institutionalized group also had an over-representation of children of Rroma (Gypsy) ethnicity and other/unknown ethnicity compared to the never-institutionalized group. There was no significant difference in gender between the two groups.

\section{METHODS}

Participants completed a touch screen-based, automated neuropsychological battery (Cambridge Neuropsychological Test and Automated Battery; CANTAB; Cambridge Cognition, Cambridge, $\mathrm{UK})$. The CANTAB focuses primarily on measuring functions of the temporal and prefrontal cortices, with tests falling into 
Table 1 | Demographics of study sample.

\begin{tabular}{llll}
\hline $\begin{array}{l}\text { Child } \\
\text { characteristics }\end{array}$ & $\begin{array}{l}\text { Institution } \\
\text { group }(\boldsymbol{n}=\mathbf{9 3})\end{array}$ & $\begin{array}{l}\text { Never } \\
\text { institutionalized } \\
\text { group }(\boldsymbol{n}=\mathbf{4 8})\end{array}$ & Significance \\
\hline $\begin{array}{l}\text { Age in months (SD) } \\
\text { Ethnicity (\%) }\end{array}$ & $103.83(4.49)$ & $102.20(4.72)$ & $p=0.047$ \\
$\begin{array}{l}\text { Romanian } \\
\text { Rroma (Gypsy) }\end{array}$ & 50.5 & 91.7 & $\chi^{2}(2)=23.40$ \\
$\quad$ Unknown/Other & 12.9 & 6.3 & $p=0.000$ \\
Gender (\%) & & 2.1 & $\mathrm{~ns}$ \\
Female & 48.4 & & \\
Male & 51.6 & 58.9 & \\
\hline
\end{tabular}

ns, nonsignificant.

three domains: visual memory, visual attention, and planning/ working memory. The CANTAB has been extensively validated for children in this age group (Luciana and Nelson, 2002).

Five subtests of the CANTAB were administered.

\section{Motor screening test}

The first subtest-a motor screening task-screens for visual, movement, and comprehension difficulties. A flashing cross is displayed on the screen in various locations, and subjects are instructed to touch it as quickly as possible. Accuracy and response latency measures are recorded. The neural correlates for this task are the corticostriatal circuitry and basal ganglia (Luciana and Nelson, 1998).

\section{Delayed matching to sample}

This subtest assesses forced choice recognition memory for patterns. The subject is shown a pattern and then must choose out of four similar patterns which one exactly matches the original pattern (see Figure 1). In some of the trials, the original pattern is obscured before the choices appear, or there is a brief delay between these steps. Outcome measures include accuracy and response latency. This task reflects the functioning of the medial temporal lobe (Luciana and Nelson, 1998).

\section{Paired associates learning}

This subtest assesses visual memory and new learning. A series of boxes is displayed, some with patterns inside, and after a brief delay the subject must identify the location of each individual pattern. If the subject does not identify each location correctly, the trial is repeated. As the subject progresses through the task, an increasing number of boxes and patterns are displayed. Stages completed, number of trials, and total number of errors are recorded. The visuo-spatial explicit memory assessed in this task is a frontotemporal function (Potvin et al., 2005).

\section{Stockings of Cambridge}

This version of the Tower of London planning task is a spatial planning task in which the subject must copy a pattern displayed on the screen by moving colored circles one at a time, using the fewest number of moves possible (see Figure 2). A key outcome measure is the number of problems that are solved in the minimum number of

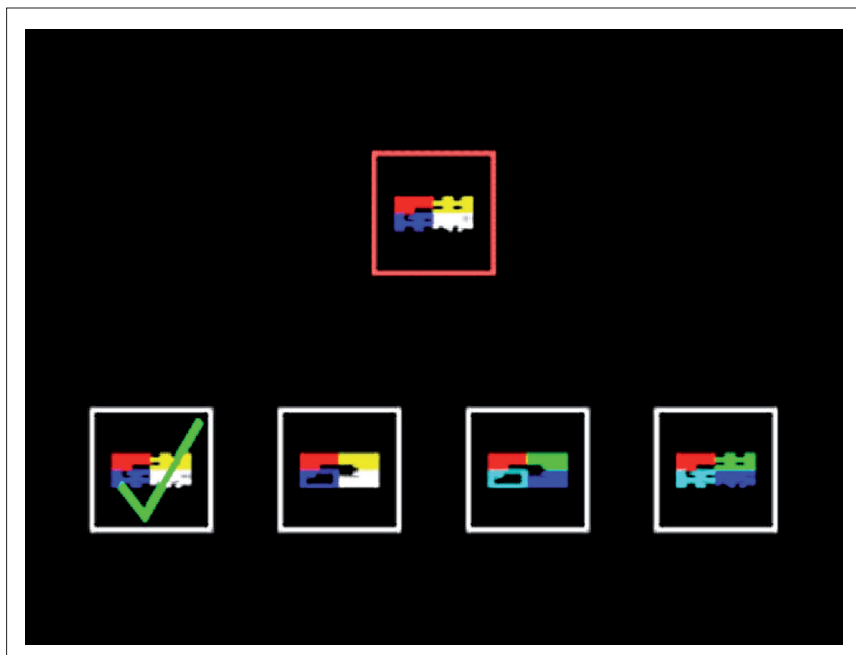

FIGURE 1 | Screen shot of one of the matching trials of the Delayed Matching to Sample subtest.

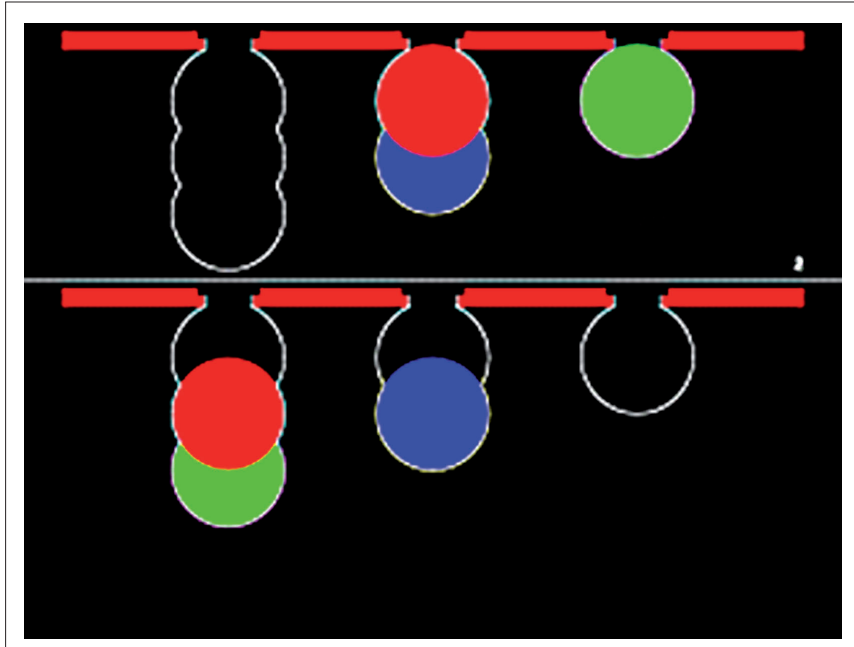

FIGURE 2 | Screen shot of one of the trials of the Stockings of Cambridge subtest.

moves. Other outcome measures include response latency time and mean moves used. This task is correlated with neural circuitry in the bilateral parietal cortices, left caudate nucleus, and left dorsolateral prefrontal cortex (Luciana and Nelson, 1998).

\section{Spatial working memory}

This subtest assesses the subject's ability to retain spatial information and to manipulate remembered items in working memory by locating tokens hidden in boxes. The subject is instructed that after a token has been found in a box, that box will not contain any tokens in the future. Subsequent stages include increasing numbers of boxes and tokens. Outcome measures include a composite strategy score, reflecting the subject's ability to search through available items in an organized method, as well as number of errors for each stage. The neural circuitry reportedly involved in this task includes the dorsal/ventral prefrontal cortex and the ascending catecholamine systems (Luciana and Nelson, 1998). 


\section{RESULTS}

There were no associations found on independent sample $t$-tests between gender and any of the measures of memory or executive function. Therefore, all subsequent analyses were performed combining boys and girls.

\section{CHILDREN WITH A HISTORY OF INSTITUTIONAL CARE}

The first question addressed was whether children with a history of institutional care performed differently on these measures of memory and executive function than children without a history of institutional care. There were no significant differences between ever-institutionalized and never-institutionalized children on the screening tests for motor skills used in these tasks. Results of key outcome measures from the CANTAB tests for visual memory and executive function tasks are reported in Table 2. Children in the EIG performed significantly worse on three of the four measures for memory and on two of the three measures for executive function.
Because we have been unable to ascertain the factors that determine initial institutional placement (the most common explanation is poverty), and because approximately $23 \%$ of the children we studied from this ever-institutionalized group were born low birth weight $(<2500 \mathrm{~g}$ ), we decided to include birth weight in our analyses as a marker to assess the role of pre- or perinatal factors. After controlling for birth weight, history of institutional care was still a significant predictor for one measure of memory and two measures of executive function (see Tables 3 and 4). In only one case (Spatial Working Memory total errors), birth weight was a significant predictor, and for this outcome, both birth weight and a history of institutional care were significant. In summary, other than for spatial working memory, we did not find an impact of birth weight on task outcomes, and controlling for birth weight did not wipe out the effects of institutional history for some measures of both memory and executive function.

Table 2 | Key outcome measures, ever-institutionalized group (EIG) and never-institutionalized group (NIG).

\begin{tabular}{|c|c|c|c|c|}
\hline Domain & Test & Outcome measure & EIG mean (SD) & NIG mean (SD) \\
\hline \multirow[t]{4}{*}{ Visual memory } & Delayed Matching to Sample & Percent correct & $56.5(16.4)$ & $66.7(13.0)^{* * *}$ \\
\hline & & Mean correct latency (ms) & $4330(1321)$ & $4086(923)$ \\
\hline & Paired Associates Learning & Mean errors to success & $3.01(2.81)$ & $2.07(2.49)^{*}$ \\
\hline & & Mean trials to success & $2.06(0.91)$ & $1.72(0.65)^{*}$ \\
\hline \multirow[t]{3}{*}{ Executive function } & Stockings of Cambridge & Problems solved in minimum moves & $5.60(2.08)$ & $6.17(1.60)$ \\
\hline & Spatial Working Memory & Total errors & $68.9(13.3)$ & $59.0(17.0)^{* *}$ \\
\hline & & Strategy score (high score = poor strategy) & $39.4(2.59)$ & $37.6(4.26)^{* *}$ \\
\hline
\end{tabular}

${ }^{*} p<0.05,{ }^{*} p<0.01,{ }^{* *} p<0.001$.

Table 3 | Regression on memory outcomes in all subjects.

\begin{tabular}{|c|c|c|c|c|c|c|c|c|c|c|c|c|}
\hline & \multicolumn{3}{|c|}{ DMS percent correct } & \multicolumn{3}{|c|}{$\begin{array}{c}\text { DMS mean correct } \\
\text { latency }\end{array}$} & \multicolumn{3}{|c|}{$\begin{array}{c}\text { PAL mean errors } \\
\text { to success }\end{array}$} & \multicolumn{3}{|c|}{$\begin{array}{l}\text { PAL mean trials } \\
\text { to success }\end{array}$} \\
\hline & $B$ & SE B & $\boldsymbol{\beta}$ & $B$ & SE B & $\boldsymbol{\beta}$ & $B$ & SE B & $\beta$ & $B$ & SE B & $\beta$ \\
\hline Birth weight (kg) & -0.36 & 2.64 & -0.01 & 40.25 & 192.50 & 0.02 & -0.72 & 0.39 & -0.18 & -0.23 & 0.13 & -0.17 \\
\hline History of institutional care & -8.78 & 3.64 & $-0.24^{*}$ & 264.05 & 264.76 & 0.10 & 0.65 & 0.54 & 0.12 & 0.26 & 0.18 & 0.14 \\
\hline Model $R^{2}$ & 0.06 & & & 0.01 & & & 0.06 & & & 0.06 & & \\
\hline
\end{tabular}

DMS, Delayed Matching to Sample; PAL, Paired Associates Learning.

${ }^{*} p<0.05$.

Table 4 | Regression on executive function outcomes in all subjects.

\begin{tabular}{|c|c|c|c|c|c|c|c|c|c|}
\hline & \multicolumn{3}{|c|}{$\begin{array}{l}\text { SOC problems solved in } \\
\text { minimum moves }\end{array}$} & \multicolumn{3}{|c|}{ SWM total errors } & \multicolumn{3}{|c|}{ SWM strategy } \\
\hline & $B$ & SE B & $\boldsymbol{\beta}$ & $B$ & SE B & $\boldsymbol{\beta}$ & $B$ & SE B & $\boldsymbol{\beta}$ \\
\hline Birth weight (kg) & 0.46 & 0.31 & 0.15 & -4.60 & 2.28 & $-0.19 *$ & -0.16 & 0.47 & -0.03 \\
\hline History of institutional care & -0.63 & 0.42 & -0.15 & 7.51 & 3.14 & $0.23^{*}$ & 1.63 & 0.65 & $0.25^{*}$ \\
\hline Model $R^{2}$ & 0.06 & & & 0.11 & & & 0.07 & & \\
\hline
\end{tabular}

SOC, Stockings of Cambridge; SWM, Spatial Working Memory.

${ }^{*} p<0.05$. 


\section{FOSTER CARE INTERVENTION}

Analyses were performed to assess the effect of the foster care intervention among children with a history of institutionalization. Independent sample $t$-tests revealed no significant differences on any of the CANTAB test outcomes between children in the care as usual (institutional care) group and children assigned to the foster care intervention.

The next analyses explored the possible role of timing and duration of institutional care on visual memory and executive functioning outcomes. Children in the foster care group were divided into two groups (younger than/older than) based on age of placement into foster care at intervals of 2 months; for example, those placed before 18 months were compared to those placed after 18 months, those placed before or after 20 months, etc. with a range of 18-28 months. The comparisons were limited by the ages of placement into foster care within this sample (mean 23.6, SD 5.88, range 9-33 months). Independent sample $t$-tests were not significant for the memory or executive function outcomes for any of these comparisons. A Pearson correlation was performed to investigate the relationship between duration of institutional care and memory and executive function outcomes. Among the children with a history of institutional care, there was no significant correlation found between any of the key outcome measures and the number of days that the child had spent in an institution prior to the age of 54 months.

\section{ADDITIONAL REGRESSION MODELS}

Within the ever-institutionalized group and the neverinstitutionalized group, we examined whether birth weight and $z$-score for head circumference at age of entry into the study might contribute to the results.

Within the ever-institutionalized group, multiple linear regression was used to examine possible relations between these two markers as well as assignment to the foster care intervention and duration of time spent in early institutional care (number of days spent in an institution prior to 54 months of age). None of these measures significantly predicted memory outcomes (see Table 5). For executive functioning outcomes, the only outcome that had any significant predictors was the Spatial Working Memory strategy score. After controlling for birth weight, head circumference, and duration of time spent in institutional care, assignment to the foster care group significantly predicted strategy scores in these everinstitutionalized children, $F(4,70)=1.90, p=0.008$ (see Table 6).

Similar multiple linear regressions performed on the neverinstitutionalized group of children revealed that birth weight and $z$-score for head circumference at age of baseline into the study did not significantly predict memory or executive functioning outcomes.

\section{ANALYSES BY LIVING SITUATION AT AGE 8 YEARS}

All of the results described above have followed an intent to treat model, with each analysis including the children in their originally

Table 5 | Regression on memory outcomes in ever-institutionalized children.

\begin{tabular}{|c|c|c|c|c|c|c|c|c|c|c|c|c|}
\hline & \multicolumn{3}{|c|}{ DMS percent correct } & \multicolumn{3}{|c|}{$\begin{array}{l}\text { DMS mean correct } \\
\text { latency }\end{array}$} & \multicolumn{3}{|c|}{$\begin{array}{l}\text { PAL mean errors } \\
\text { to success }\end{array}$} & \multicolumn{3}{|c|}{$\begin{array}{l}\text { PAL mean trials } \\
\text { to success }\end{array}$} \\
\hline & $B$ & SE B & $\beta$ & $B$ & SE B & $\beta$ & $B$ & SE B & $\beta$ & $B$ & SE B & $\boldsymbol{\beta}$ \\
\hline Birth weight (g) & 0.00 & 0.00 & -0.09 & -0.23 & 0.26 & -0.12 & 0.00 & 0.00 & -0.15 & 0.00 & 0.00 & -0.10 \\
\hline Z-score for head circumference for age & -0.35 & 2.06 & -0.02 & 52.89 & 160.75 & 0.04 & 0.02 & 0.31 & 0.01 & -0.02 & 0.11 & -0.02 \\
\hline Randomized to foster care intervention & -9.78 & 5.11 & -0.31 & -308.46 & 399.08 & -0.13 & 0.02 & 0.76 & 0.01 & -0.05 & 0.27 & -0.03 \\
\hline Model $R^{2}$ & 0.07 & & & 0.02 & & & 0.04 & & & 0.03 & & \\
\hline
\end{tabular}

DMS, Delayed Matching to Sample; PAL, Paired Associates Learning.

Table 6 | Regression on executive function outcomes in ever-institutionalized children.

\begin{tabular}{|c|c|c|c|c|c|c|c|c|c|}
\hline & \multicolumn{3}{|c|}{$\begin{array}{l}\text { SOC problems solved in } \\
\text { minimum moves }\end{array}$} & \multicolumn{3}{|c|}{ SWM total errors } & \multicolumn{3}{|c|}{ SWM strategy } \\
\hline & $B$ & SE B & $\boldsymbol{\beta}$ & $B$ & SE B & $\boldsymbol{\beta}$ & $B$ & SE B & $\beta$ \\
\hline Birth weight (g) & 0.00 & 0.00 & 0.10 & 0.00 & 0.00 & -0.13 & 0.00 & 0.00 & -0.03 \\
\hline Z-score for head circumference for age & -0.31 & 0.25 & -0.16 & -0.53 & 1.79 & -0.04 & 0.19 & 0.30 & 0.08 \\
\hline Randomized to foster care intervention & 0.45 & 0.62 & 0.12 & -5.90 & 4.43 & -0.21 & -2.05 & 0.75 & $-0.43^{*}$ \\
\hline Number of days in institutional care & 0.00 & 0.00 & 0.27 & -0.01 & 0.01 & -0.25 & 0.00 & 0.00 & -0.24 \\
\hline Model $R^{2}$ & 0.06 & & & 0.07 & & & 0.10 & & \\
\hline
\end{tabular}

SOC, Stockings of Cambridge; SWM, Spatial Working Memory.

${ }^{*} p<0.01$. 
assigned group. However, a significant number of children have changed group status since the beginning of the study. These changes have particularly affected children within the care as usual (originally, institutional care) group. At the age of 8 years, of the 44 children for whom we have CANTAB data on in the care as usual group, only 11 children were still institutionalized. The remaining 33 children had the following living situation: three were adopted, one was placed with a family, 15 were in government foster care, and 14 were reintegrated with their biological families.

Independent sample $t$-tests were performed within the original care as usual group, comparing children still living in the institution at age 8 years with children placed out of the institution by this point. No significant differences were found on any of the CANTAB test outcomes between these two groups.

\section{DISCUSSION}

We first investigated whether children who have been exposed to early deprivation in an institutional care setting perform differently on tests of visual memory and executive functioning than their peers without a history of early institutional care. The results indicate deficits in both of these domains among children with a history of early institutional care, suggesting a pattern of impairment in this population associated with specific neural structures, for example, the medial temporal lobe (including the hippocampus) and the prefrontal cortex. These findings are consistent with previous work on the effects of early institutional deprivation, including neuroimaging and neuropsychological studies (Chugani et al., 2001; Colvert et al., 2008; Pollak et al., in press). These results contribute to our understanding of the specific cognitive processes that may be affected by the deprivation associated with early institutional care.

To clarify the role of pre- or perinatal factors in children with a history of institutional care, we examined the role of birth weight in this population. For one outcome, Spatial Working Memory total errors, birth weight as well as history of institutionalization were both significant predictors. A previous study by Curtis et al. (2002) also found significant impairment on this task for children who were born prematurely or with medical complications requiring care in a neonatal intensive care unit. These findings suggest that the areas of the brain involved in this task, the dorsal and ventral regions of the prefrontal cortex, may be particularly impacted by pre- or perinatal neurobiological risk.

The finding that for all outcomes except for Spatial Working Memory total errors, birth weight was not a significant predictor is also important in clarifying the role of pre- or perinatal factors in this population. Any history of institutional care was still a significant predictor after controlling for birth weight for some outcomes of both memory and executive function, specifically, Delayed Matching to Sample percent correct, Spatial Working Memory total errors, and Spatial Working Memory strategy score. By controlling for a marker of pre- or perinatal conditions, this finding extends previous results in the literature that have identified an impact of institutional care on these cognitive domains.

We next addressed the question of whether institutionalized children randomly assigned to a foster care intervention perform better than their peers who have continued care in the institution. Initial comparisons between the CAU and the FCG did not reveal significant differences on any of the memory or executive functioning outcomes. However, for the Spatial Working Memory strategy score, after controlling for birth weight, head circumference, and duration of time spent in early institutional care, the foster care intervention was a significant predictor of scores. Since the children in this study were randomly assigned to placement into a foster care setting or continued care as usual in the institution, these findings are able to avoid some of the sample bias inherent to other research of children adopted out of institutions, and therefore provides additional support for the findings of previous studies in suggesting the beneficial effects of family placement on executive functioning abilities.

Within the group of children assigned to the foster care intervention, we further investigated the effects of timing of foster care placement. We did not identify any significant effects of timing of placement into foster care for either memory or executive functioning. However, one important limitation to our study is that the children were placed into foster care at a relatively old age (average age of placement of 23.6 months, with a range of 9-33 months). The ERAS study of Romanian adoptees found effects of timing of placement on executive functioning outcomes using the much younger placement cut-off of 6 months: children adopted out of Romanian institutions after the age of 6 months were found to differ significantly from a comparison group of within the United Kingdom adoptees with no history of institutional care, while children adopted out of Romanian institutions before the age of 6 months did not differ significantly from the within-UK adoptees (Colvert et al., 2008). The findings in the current study do not rule out the possibility of significant effects in these domains for children placed earlier into a foster care placement and, taken together with the results of the ERAS study, may in fact underscore the importance of family placement at a very young age rather than institutional care for abandoned children.

Finally, we analyzed the outcomes of children originally assigned to the care as usual group based on their living situation at age 8 years, when this data was collected. We did not find any significant differences between children still living in institutions and children who had been placed out of the institution at this point. It should be noted that there was not random assignment between these two groups, and there are likely many differences between children placed out of the institutions earlier and those who remain in the institution. However, this makes our findings of no differences on these outcomes at age 8 years more surprising and may provide further support for the importance of very early experience in influencing these outcomes.

There are several limitations that should be noted for this study. First, as previously mentioned, the mean age of placement into foster care for participants in this study was nearly 2 years and thus the study is unable to address the potential consequences of earlier placement into foster care on the developmental trajectory in these domains. Second, the data collected on memory and executive function abilities are cross-sectional, not longitudinal, and only provide information on these outcomes at the age of 8 years. Future work should be done to investigate if the results found here persist into adolescence and adulthood. Third, Romanian institutions may not be representative of some institutions in other countries, and therefore these results may not be generalizable to all children with a history of early psychosocial deprivation or institutionalization. 
In conclusion, these results support and extend previous findings of deficits in memory and executive functioning among school-age children with a history of early deprivation due to institutional care. On further investigation within the group of everinstitutionalized children, we identified differences in executive functioning outcomes, with children randomly assigned to the foster care intervention performing better on some of these measures than children who had continued care in the institution. These findings have implications for the millions of children who continue

\section{REFERENCES}

Beckett, C., Maughan, B., Rutter, M., Castle, J., Colvert, E., Groothues, C., Kreppner, J., Stevens, S., O'Connor, T. G., and SonugaBarke, E. J. S. (2006). Do the effects of early severe deprivation on cognition persist into early adolescence? Findings from the English and Romanian adoptees study. Child Dev. 77, 696-711.

Chisholm, K. (1998). A three year followup of attachment and indiscriminate friendliness in children adopted from Romanian orphanages. Child Dev., 69, 1092-1106.

Chugani, H. T., Behen, M. E., Muzik, O., Juhasz, C., Nagy, F., and Chugani, D. C. (2001). Local brain functional activity following early deprivation: a study of postinstitutionalized Romanian orphans. Neuroimage 14, 1290-1301.

Colvert, E., Rutter, M., Kreppner, J., Beckett, C., Castle, J., Groothues, C., Hawkins, A., Stevens, S., SonugaBarke, E. J. S. (2008). Do theory of mind and executive function deficits underlie the adverse outcomes associated with profound early deprivation?: findings from the English and Romanian adoptees study. J. Abnorm. Child Psychol. 36, 1057-1068.

Curtis, W. J., Lindeke, L. L., Georgieff, M. K., and Nelson, C. A. (2002). Neurobehavioral functioning in neonatal intensive care unit graduates in late childhood and early adolescence. Brain 125, 1646-1659.

Greenough, W. T., Black, J. E., and Wallace, C. E. (1987). Experience and brain development. Child Dev. 58, 539-559.

Jurado, M. B., and Rosselli, M. (2007). The elusive nature of executive functions: a review of our current understanding. Neuropsychol. Rev. 17, 213-233.

Kreppner, J. M., O'Connor, T. G., Rutter, M., and the English and Romanian Adoptees Study Team. (2001). Can inattention/overactivity be an institutional deprivation syndrome? J. Abnorm. Child Psychol. 29, 513-528.

Luciana M., and Nelson, C.A. (1998). The functional emergence of prefrontallyguided working memory systems in four- to eight-year-old children. Neuropsychologia 36, 273-293.

Luciana, M., and Nelson, C. A. (2002). Assessment of neuropsychological function through use of the Cambridge Neuropsychological Testing Automated Battery: performance in 4- to 12-Year old children. Dev. Neuropsychol. 22, 595-624.

McEwen, B. S. (2007). Physiology and neurobiology of stress and adaptation: 87, 873-904.

Nelson, C.A., III, Zeanah, C.H., Fox, N. A., Marshall, P. J., Smyke, A. T., and Guthrie, D. (2007). Cognitive recovery central role of the brain. Physiol. Rev.

to experience the psychosocial deprivation associated with early institutional care.

\section{ACKNOWLEDGMENTS}

The work reported in this manuscript was supported by the John D. and Catherine T. MacArthur Foundation, the Binder Family Foundation and the Richard David Scott Chair (to Charles A. Nelson) and the Doris Duke Charitable Foundation (to Karen Bos).

in socially deprived young children: the Bucharest Early Intervention Project. Science 318, 1937-1940.

Pollak, S. D., Nelson, C. A., Schlaak, M., Roeber, B., Wewerka, S., Wiik, K., Frenn, K., Loman, M., Gunnar, M. (in press). Neurodevelopmental effects of early deprivation in postinstitutionalized children. Child Dev.

Potvin, S., Briand, C., Prouteau, A. Bouchard, R., Lipp, O., Lalonde, P., Nicole, L., Lesage, A., and Stip, E. (2005). CANTAB explicit memory is less impaired in addicted schizophrenia patients. Brain Cogn. 59, 38-42.

Richmond, J., and Nelson, C. A. (2007). Accounting for change in declarative memory: a cognitive neuroscience perspective. Dev. Rev. 27, 349-373.

Smyke, A. T., Koga, S. F., Johnson, D. E. Fox, N.A., Marshall, P. J., Nelson, C.A., and Zeanah, C.H. (2007). The caregiving context in institution-reared and family-reared infants and toddlers in Romania. J. Child Psychol. Psychiatr. 48, 210-218.

United States Department of State (2009). Total Adoptions to the United States. Available at: http://adoption.state.gov/ news/total_chart.html (Retrieved 21 July 2009).

Zeanah, C. H., Nelson, C. A., Fox, N. A., Smyke, A. T., Marshall, P. Parker, S. W., and Koga, S. (2003). Designing research to study the effects of institutionalization on brain and behavioral development: the Bucharest Early Intervention Project. Dev. Psychopathol. 15, 885-907.

Zeanah, C. Z., SMyke, A. T., Koga, S. F., Carlson, E., and The BEIP Core Group. (2005). Attachment in institutionalized and community children in Romania. Child Dev. 76, 1015-1028.

Conflict of Interest Statement: The authors declare that the research was conducted in the absence of any commercial or financial relationships that could be construed as a potential conflict of interest.

Received: 22 May 2009; paper pending published: 08 June 2009; accepted: 03 August 2009; published online: 01 September 2009.

Citation: Bos K, Fox N, Zeanah $\mathrm{CH}$ and Nelson CA (2009) Effects of early psychosocial deprivation on the development of memory and executive function. Front. Behav. Neurosci. 3:16. doi 10.3389/neuro.08.016.2009

Copyright (C) 2009 Bos, Fox, Zeanah and Nelson. This is an open-access article subject to an exclusive license agreement between the authors and the Frontiers Research Foundation, which permits unrestricted use, distribution, and reproduction in any medium, provided the original authors and source are credited. 